\title{
THE USE OF 3D BUILDING DATA FOR DISASTER MANAGEMENT: A 3D SDI PERSPECTIVE
}

\author{
Umroh Dian Sulistyah ${ }^{1}$, Jung-Hong Hong ${ }^{2 *}$ \\ ${ }^{1}$ Master Student, Department of Geomatics, National Cheng Kung University, Taiwan - umrohdians@gmail.com \\ ${ }^{2}$ Professor, Department of Geomatics, National Cheng Kung University, Taiwan - junghong@ mail.ncku.edu.tw
}

KEY WORDS: 3D Spatial Data Infrastructure (3D SDI), 3D Building, CityGML, Disaster Management, Semantic

\begin{abstract}
:
In recent years, the demands of 3D cyber-city have been steadily growing. With strong links to the citizens' lives, building information is considered as the most important component in the 3D urban model. To further facilitate the best usage of 3D data, the development of 3D SDI requires creative thinking to meet different application needs. While many current applications are restricted to visualization only, we argue the 3D building data in 3D SDI must at least consider the issues of feature modelling, identification, semantics, level of details, cross-domain linking and services. This paper intends to assess the use of the semantic-enriched 3D building data in the applications of disaster management. Based on CityGML, we first create 3D building data based on a hierarchy of building-storeyhousehold representation. Identifier systems are respectively developed for each level of features for the purpose of identifying individual features and linking to other sources of data, e.g., the household registration information. By reviewing and comparing the outcomes of the past research of 3D flood simulation, we demonstrate the improved 3D building data additionally enables the direct impact analysis at the chosen level of features, as well as visually present enriched analyzed outcomes for decision making, e.g., the number of trapped people in specific floor. As the merits of the SDI is to share reliable information, encourage multiple-purpose applications and avoid duplicated spending, we thereby conclude the necessity to further examine the level of details and multiple representation of the serviced 3D building data for cost-effective and cross-domain application development.
\end{abstract}

\section{INTRODUCTION}

The dynamic nature of the emergency situation requires a real time update of various data / information obtained from various organizations because there is no individual institution that can produce and update all necessary information. Herzog et al (2007) argue it is more effective to match data from various administrative data sources rather than develop new surveys to collect new data that are often already present in a dataset. Partnerships, data sharing, and data exchange between stakeholders are therefore necessary. However, due to various types of heterogeneity, finding and integrating data from disparate sources remain a major obstacle to the emergency response agencies. Spatial Data Infrastructure (SDI) has been developed in close collaboration with the intended organizations. With SDI (Rajabifard et al, 2004), it is possible to facilitate and coordinate exchanges and sharing of spatial and non-spatial data across different disciplines and organizations. This could make users save time, resources, and efforts in obtaining datasets that fit their applications needs. Moreover, the system can avoid duplicates of data and expenses in making, maintaining, and integrating datasets from different domains. Simply to put, SDI enables the ultimate goal of "create data once and used many times" (EU, 2007).

In the geospatial domain, applications are steadily moving from conventional $2 \mathrm{D}$ maps to $3 \mathrm{D}$ realistic representations. An increasing number of successful 3D geospatial applications are widely used in various application fields for diverse purposes, such as disaster management, urban management and planning, land use monitoring, solar radiation potential assessment, pollutant diffusion, virtual tour, navigation, gaming, etc. (Moreira et al. 2013). The use of 3D data, as well as its benefits in all types of spatial analysis, are capable of offering better and more comprehensive results to the decision making support in project related to locations (Jafari Salim, M., 2017). Therefore, the success of future geospatial technology demands an innovated and in-depth exploration from the 3D perspective. Being widely accepted in the 3D SDI literatures, CityGML is an OGC standard for the representation, storage and exchange of virtual 3D city and landscape (Kolbe, 2009). CityGML is a model designed to cope with the modelling of the geometry and semantics of the selected list of city phenomena in a standardized way. As a standard, CityGML has been widely used to facilitate the interoperable data exchange and application development between different agencies. Moreover, CityGML also provides an extended mechanism, the Application Domain Extension (ADE), to additionally design more feature types or adjust the properties to existing feature types to address different domain usage (Gröger and Plümer, 2012). An ADE is defined to adapt CityGML to particular application domain demands. One of the successful model of this extension come from Chen et al (2019) that use the Energy ADE to integrate the building spatial and physics properties for visualization 3D urban building energy modelling. Furthermore, the new national standard in the Netherlands will be implemented CityGML ADE for cadastral domain with support of a 3D parcel object class (Stoter et al., 2011). From the perspective of geospatial data, 3D SDI based upon CityGML shall serve as a solid foundation for coordinating the resources of related stakeholders and facilitating the effective decision making in disaster management.

There are some specific 3D features types already defined with semantics in the CityGML models, such as buildings, terrain, roads, river, bridges, etc. Yang et al. (2000) argued buildings are the most common feature type in the 3D urban model. Another study by Xuan (2015) also stated that building model plays a significant role as a major component of the urban space environment in almost all urban GIS. If 3D buildings are not considered, the datasets can hardly be seen as an appropriate representation of the city phenomena. This study focuses on the role and structure of 3D buildings and its usage in selected 
applications, such as disaster management. In terms of the modelling of different aspects of buildings, one of the characteristics must be considered is the strong link building and citizens' lives. For example, building information plays an extremely important role in risk reduction since they represent human settlements in villages and cities (Skakun et al. 2014). Furthermore, most of the population distributions can be estimated from buildings (Ehrlich, 2013). Hence the design shall not only consider the physical properties of the buildings, but also the census properties associated with buildings. This study therefore proposes to model the 3D building with a buildingstorey-household hierarchy, such that attribute information associated with these three different levels of spatial units can be respectively designed to meet different application needs.

The remaining of the paper is organized as follows. Section 2 explains the methodology used in this paper by mainly exploring the 3D modelling of buildings in SDI. Section 3 summarizes the major approaches used in flood related research. Section 4 demonstrates how the designed building data is used in flood disasters. Finally, section 5 concludes our major findings and suggests future works.

\section{METHODOLOGY}

The discussion in this section intends to first assess the design of 3D building data from the 3D SDI perspective, then explore how the $3 \mathrm{D}$ building data can be shared and used in other applications.

\subsection{D Building in 3D SDI Perspective}

In the development of building spatial data, the geospatial world has moved towards $3 \mathrm{D}$. This is in line with the many applications in various fields that apply $3 \mathrm{D}$ as a solution. Spatial Data Infrastructure (SDI) also has changed with the rapid advanced 3D modelling technology and the open standards infrastructure. Some countries have developed and implemented 3D SDI, such as The Netherlands, Oman, and Malaysia (Stoter J. et al, 2011; Kalbani K. et al, 2018; Alias A. et al, 2010).

The 3D city model has several city features consisting of buildings, roads, rivers, bridges, vegetation, etc. With its importance to support humans' daily lives, 3D building is an essential and indispensable component to the $3 \mathrm{D}$ city modelling. To be able to support the usage for any application that requires 3D building data, it is necessary to consider how to model the various aspects of $3 \mathrm{D}$ building and how to integrate the modelling results with other domain data according to the purpose of the intended applications. With open GIS standards, the sharing of 3D building information has become easier, but further consideration from the SDI perspective is still necessary.

Most government data have explicit or implicit geospatial component. Policies vary from country to country and even jurisdiction to jurisdiction. The development of SDI typically requires core data (and services) to serve as the foundations for SDI, such that the quality and availability of commonly used data can be guaranteed via rigorous and professional consideration. The SDI architecture also need to consider how to build partnerships with other domain stakeholders, so that their georesources can be included and shared. Without SDI, there will be unnecessary duplicates of data that may require tremendous spending. The collaboration of related stakeholders enables the creation of data by authorized stakeholders with professional consideration, the distribution of geospatial resource via open GIS standards and the development of interoperable applications with shared geospatial resources. The key merits are users can easily search and acquire the required data, understand its content and quality and then correctly use the data in their applications.

Using CityGML as the standard and the open and standardized data in SDI, various 3D application can be readily developed. In addition, it is important to manage 3D building model data in maximizing 3D spatial queries searches (Uznir, et al. 2014). In the 3D city model, CityGML defines five different scales for modelling 3D buildings, well known as the Level of Details (LoD). The LoDs are required to reflect independent data collection process with differing application requirements. Furthermore, LoDs could facilitate data visualization and analysis efficiently. The standard defines buildings in LoD 0 as building represented by the footprint and/or roof edge of polygons ( $2 \mathrm{D}$ shape in $3 \mathrm{D}$ space). If the building is represented in both footprint and the roof edge polygon, polygons will be stored separately. This implies LoD 0 does not contain volume information (but 3D illustration by GIS software is still possible). Buildings of LOD 1 adopts the famous block model, such that the modelling results consist of prismatic buildings that have a flat roof structure. Buildings of LOD 2 can model complex roof structure and boundary surfaces with semantics. For LoD 3 and LoD 4, buildings are modelled in more details city model for outdoor and indoor applications, which requires a high level of accuracy in its implementation. In the LoD 3 model, the walls and roof structure are shown in detail, as well as the doors and windows. The LoD 4 complements the LoD 3 model by adding the interior structure of the building. For example, buildings in the LoD 4 will have rooms, stairs, interior doors and furniture (Biljecki, 2017).

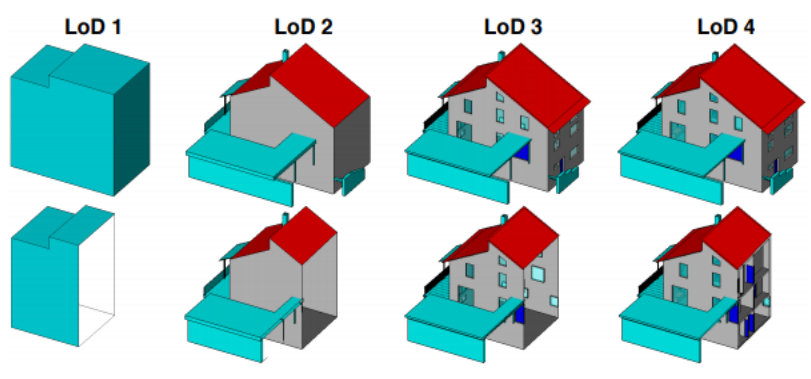

Figure 1. Four LoDs of CityGML (Courtesy of Karlsruhe Institute of Technology) (Biljecki, 2017)

\subsection{Hierarchy of Building-Storey-Household: Semantic Enriched of 3D Building Data}

Along with the evolved of technology, 3D building has become useful beyond visualization for several reasons and could be used in a big amount of fields. To improve the use of 3D building data, the geometric structure of the building is not the only thing that needs to be considered but also needs to enrich the semantic information of the building. Semantic enrichment of building model leads to the addition of meaningful information with automatically or even semi-automatically into $3 \mathrm{D}$ building model or other structures by using software that could assist in the process of concluding new information (Belsky et al. 2016). Semantic enrichment is become important because of the wide use in the multidimensional urban environment and the complexity of its structure. The approach in the semantic modelling as well as the appliance of 3D geometry and topology of real-world objects is realized by the open data model in the CityGML standard. It is the first semantic 3D standard which not only represents the shape and graphical appearance of 3D city models but specifically consider object semantics and 
representations in thematic, aggregation, and taxonomies (Kolbe, 2009).

Semantic model enrichment development is driven by the issue of interoperability of data (Eastman et al. 2008), which hampers the use of 3D building data for various applications and causes difficulties for software for exchanging data. Kubicek et al (2011) discusses the interoperability issue from three main perspectives: the technical, the semantic and the organizational interoperability. Within 3D SDI concept, the hierarchy of building-storey-household proposed in this paper is intended to tackle the interoperability issues from semantic and organizational interoperability perspectives by using CityGML as a standard for integrating data from various domains by improving semantically enriched information of 3D building in the application of disaster management.

The input is the existing 3D building model, coupled with building attribute information obtained from different sources/databases (e.g. the number of storeys of the building, the number of people living in the building, etc) and also a set of rules that encompasses expert knowledge of the domain. The rules use the existing information and evaluate the topological, spatial, geometric, and other relationships between the model's objects. The output is a digital 3D building model (geometrical structure) with the new information/new objects such as storeys information, household data, population data, etc. Although semantic enrichment generally is considered to be applied to add missing information to the building model, it also has been applied to extend the schema of building information models.

The hierarchy of building-storey-household representation purposed has three different levels, where the highest level is building, then followed by storey and household. Conceptual speaking, each level has its own geometric structure and attributes and aggregation relationships can be defined between these three levels of features. Using the building geometry and additional semantic information about the building (e.g. building usage, number of storey, etc.), it able to improve the information value from each building. Through the integration of data at each level, the most bottom level will be recording the most detailed information.

2.2.1 Building Level: A building is described consist of several numbers of storey where each of it occupied by one or more households. In this level, each building will have information about the geometry and attributes information. By having the geometry structure of the building, we can estimate which buildings are affected by the flood and directly analyzed the impact of it on building through the visualization results. Afterwards, the number of people trapped in the building could be analyzed when a disaster happens. The building attributes consist of unique building identification number (GMLID) and others building information which could be assess to many kind of aspects such as humans 'live/population, education, insurance, etc. This study focus on how building data attached with humans 'live in disaster management. Table 1 shows the list of attribute information at the building level.

\begin{tabular}{|l|l|}
\hline \multicolumn{1}{|c|}{ Attribute Name } & \multicolumn{1}{c|}{ Description } \\
\hline GMLID & $\begin{array}{l}\text { Unique building } \\
\text { identification number. } \\
\text { The street address of } \\
\text { building. } \\
\text { The house number of } \\
\text { building. }\end{array}$ \\
\hline
\end{tabular}

\begin{tabular}{|c|c|}
\hline ZIP_CODE & The zip code of building. \\
\hline CITY & $\begin{array}{l}\text { The city where the } \\
\text { building located. }\end{array}$ \\
\hline COUNTRY & $\begin{array}{l}\text { The country where the } \\
\text { building located. }\end{array}$ \\
\hline YEAR_OF_CONSTRUCTION & $\begin{array}{l}\text { The year construction of } \\
\text { building. }\end{array}$ \\
\hline BUILDING_HEIGHT (m) & $\begin{array}{l}\text { The total height of } \\
\text { building (include the } \\
\text { roof part). }\end{array}$ \\
\hline NUMBER_OF_FLOORS & $\begin{array}{l}\text { The total number of } \\
\text { floors of building. }\end{array}$ \\
\hline HIGHEST_FLOOR & $\begin{array}{l}\text { The highest floor owned } \\
\text { by the building. }\end{array}$ \\
\hline LOWEST_FLOOR & $\begin{array}{l}\text { The lowest floor owned } \\
\text { by the building. }\end{array}$ \\
\hline BUILDING_USAGE & $\begin{array}{l}\text { The usage of building } \\
\text { (e.g. residential, office, } \\
\text { shopping center, hotel, } \\
\text { storage, etc). }\end{array}$ \\
\hline NUMBER_OF_HOUSEHOLDS & $\begin{array}{l}\text { The total number of } \\
\text { households occupying } \\
\text { the building. }\end{array}$ \\
\hline
\end{tabular}

Table 1. Building data description

2.2.2 Storey Level: Each storey level is identified with SID where it located in a specific building and has a level of height. Each of storey has its own geometry and attribute information. In this level of hierarchy, the total number of household and the total number of population could be illustrated in each storey. Every storey has their own purpose, but most of them are used as a residential area.

\begin{tabular}{|l|l|}
\hline \multicolumn{1}{|c|}{ Attribute Name } & \multicolumn{1}{c|}{ Description } \\
\hline GID & $\begin{array}{l}\text { Unique storey } \\
\text { identification number. } \\
\text { The house number of } \\
\text { building number. } \\
\text { The floor number of } \\
\text { building (e.g. } 1^{\text {st }} \text { floor, } 2^{\text {nd }} \\
\text { floor, etc). } \\
\text { The total number of } \\
\text { households in a certain } \\
\text { floor. } \\
\text { The total number of } \\
\text { population in a certain } \\
\text { floor. }\end{array}$ \\
\hline TOTAL_OF_POPULATIOREYHOUSEHOLDS
\end{tabular}

Table 2. Storey data description

2.2.3 Household Level: In household level, it illustrates the number of people in a household who live in the specific floor and has the information about the characteristic of people in every household. It has HID as its identifier. By connecting HID with BID and SID, then the detail information of the address where the households live could be found. There are 4 categories of age in this data which is $(0-15)$ years old, (16-30) years old, (31-55) years old, and (56-100) years old. With this information, it can be known the number of people who live in a household and their age to prioritize the evacuation process when the disaster happens.

\begin{tabular}{|l|l|}
\hline \multicolumn{1}{|c|}{ Attribute Name } & \multicolumn{1}{c|}{ Description } \\
\hline HID & $\begin{array}{l}\text { Unique household } \\
\text { identification number. }\end{array}$ \\
\hline
\end{tabular}




\begin{tabular}{|c|c|}
\hline SID & Unique storey identification \\
\hline GMLID & $\begin{array}{l}\text { number. } \\
\text { The house number of building } \\
\text { number. }\end{array}$ \\
\hline NUMBER_OF_PEOPLE & $\begin{array}{l}\text { The total number of households } \\
\text { in a certain floor. }\end{array}$ \\
\hline $\operatorname{AGE}(0-15)$ & $\begin{array}{l}\text { The number of people aged } 0 \text { - } \\
15\end{array}$ \\
\hline AGE (16-30) & $\begin{array}{l}\text { The number of people aged 16- } \\
30\end{array}$ \\
\hline AGE (31-55) & $\begin{array}{l}\text { The number of people aged - } \\
31-55\end{array}$ \\
\hline AGE (56-100) & $\begin{array}{l}\text { The number of people aged 56- } \\
100\end{array}$ \\
\hline
\end{tabular}

Table 3. Household data description

\subsection{Integrating Information through Unique Identification Number}

This study implemented the hierarchy of building-storeyhousehold representation in disaster management applications. Disaster management represents the interface between human systems and the environment. From this perspective, this is part of a multidimensional domain including environmental issues, the private sector and the public as well as citizens. However, each domain has its own standard therefore to form a good management system requires interoperability of these data. With the standardization in the SDI concept, could make SDI as an essential part of interoperability data and information on the disaster management domain. The SDI represents an enormous environmental data harmonization effort at the specific level of region, and its cover several thematic domains from the government, large number of experts and organizations which involved in its development. As the result, the process of linking data in different domain become possible to implement in this study where building data and its feature will be linked with population data to get a better illustration about the impact of natural disaster.

In order to facilitate updates of CityGML features and support the retrieval additional information, it is common practice to have an external reference pointing to the identifier of the object in another information system in CityGML (Gröger and Plümer, 2012). Integrating and matching information from multiple building databases can improve data quality. To correctly attach a variety of data to a building, the building (or a portion of a building) needs to be identified with an external key which is a field in a relational database that uniquely identifies database records. Unique identification for buildings will provide a standardized framework under which a unifying field is used to match building data from various sources to a single object or use the ID to combine with other data types according to the application domain. It will facilitate data management and sharing by reducing the risk of mismatching or duplicating building data, and it will ease the burden of data exchange.

The attribute information of each level of hierarchy has the unique identification number on each object. The identification number for building level, storey level, and house level are GMLID, SID, HID, respectively. Through these IDs, it could provide links to the relevant visualization, documentation, and management. The 3D building model could be joined to 3D CityDB (3D City Database), according to the different LoD selected, thus connecting to the relevant part of the unique ID (GMLID, SID, and HIS). Figure 2 present the linkage from building level (LoD2) to more detailed level of single household within buildings (LoD4).
The ID number on building level is based on the ID number of building objects recorded by 3D building model (GMLID). Furthermore, the ID number for the storey level (SID) is given by the author based on the last 6 digits of GMLID plus the number of ID which identify the floor number in the building. Whereas at the household level, the ID number (HID) was consist of $\mathrm{H}-$ letter which means 'Household' and 6 digit numbers. This ID number was given by the author. The following table is an example ID from each level of the hierarchy.

\begin{tabular}{|l|l|}
\hline Level of Hierarchy & \multicolumn{1}{|c|}{ ID Number } \\
\hline GMLID & $\begin{array}{l}\text { ID_0599100000661104 } \\
\text { 661104F2 (It means located in 2 } \\
\text { SID } \\
\text { floor) } \\
\text { HID }\end{array}$ \\
\hline
\end{tabular}

Table 4. Example of ID in each level of hierarchy

Table 4 illustrates the example of the information from the level of hierarchy. When one building is selected, the detail information about the building will appear such as the building height, year of construction, address, etc. After it connected with the level of hierarchy, the information of the storey will show up and give an information about the number of storey that building has, and also the number of household who live in the storey. Moreover, the member of household also can be view by selecting specific floor and choose one of the household.

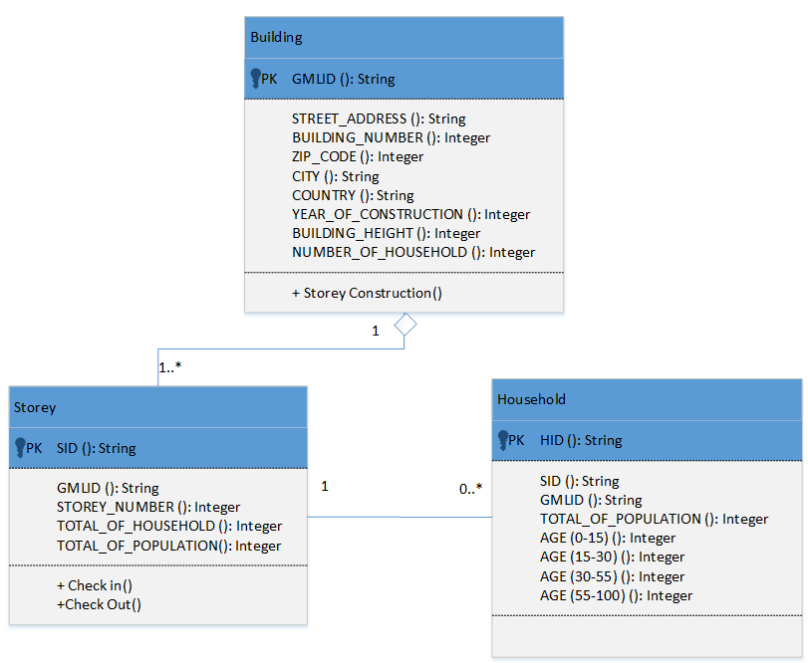

Figure 2. The UML of hierarchy building-storey-household

\section{REVIEW OF 3D FLOOD SIMULATION}

Ten previous studies have been reviewed to assess the data used in 3D flood visualization. In general, the data can be categorized into 3 different datasets, namely infrastructure element dataset, flood hazard spatial dataset, and social indicators dataset. In the infrastructure element dataset, all of the studies emphasized the use of building data in flood visualization, especially in the form of 3-dimensional data. Therefore, it can be concluded that the building is an important feature to analyze the direct impact of the flood. Most of the research used LIDAR to generate the 3D building. On the other hand, Kumar et al (2018) used glTF format to visualize the 3D buildings. In general, they only focus on 3D building visualization to find out the affected area by flood in the city. The previous studies, the 3D building data cannot provide more detailed information about social indicator in each building. 
Another study from Costas et al (2017), they considered the social indicators dataset in their model such as age, population, etc. However, social data only describes an area as a whole.

In modelling floods, all reviewed studies used DEM data to visualize floods. In addition, several data are also used to support the flood modelling, such as rainfall, satellite image, orthophoto. One study even obtained a flood risk zone map that can be directly used for visualization.

Based on the previous study, none of them is used enriched semantic on the 3D building. Therefore, we proposed the hierarchy of building-storey-household to demonstrate the improved 3D building data additionally enables the direct impact analysis at the chosen level of features. With this improvement, it able to show the information about the affected building by flood and the number of people who trapped in each of building.

\section{IMPLEMENTATION AND DISCUSSION}

\subsection{Study Area and Dataset}

The study area was the city of Rotterdam, Netherlands. The 3D Building data obtained from Rotterdam 3D which is an open data website for 3D building. The building data downloaded in LoD2 with CityGML format. Rotterdam 3D not only provide the building data. Tree, lamppost and cable and pipes are available and can be accessed in 3D. Other used data was Digital Elevation Model (DEM) data from Open DEM EU with $0.5 \mathrm{mx} 0.5 \mathrm{~m}$ resolution. DEM data used as the input for generating the terrain model of the study area. In addition, the attribute information associated with these three different levels of spatial units in the hierarchy of building-storey-household can be respectively designed. Later on, the disaster simulation that will be applied in this study is flood. As the results, we could analyze visually the impact of the flood and analyze the number of people who were affected by flooding in a certain building and floor. As the result, this case will be help to improve the decision making process.

\subsection{Flood Simulation Framework}

Figure 3 depicts the framework of this study for simulating 3D building data in the hierarchy of building-storey-household and visualizing flood as a case in disaster management. The details implementation of this framework are explained in Section 4.3.

\subsection{Implementation}

First, 3D building data was created based on the hierarchy of building-storey-household representations. The attribute information used in this simulation are building, storey, and household data (Table 1, 2, and 3). In this study, 3D building data only has a geometric structure in single building. So that in its implementation in hierarchy, the geometry structure of the storey level and household level cannot be shown. By integrating this building data will enrich the semantic information of 3D building related to the population for further analysis. For visualization, 3D building data is converted into multipatch LoD2.

Later on, the DEM is used to perform hydrological models. Flood Modeller was use for generating the time-series of water depth in the study area. Flood Modeller is an open-source flood simulation software which leads to $1 \mathrm{D}$ and $2 \mathrm{D}$ hydraulic solvers to seamlessly rivers models, floodplains, and urban drainage systems. The DEM data needs to convert in DEM ASCII format and takes as input in Flood Modeller. In addition, several parameters need to be set such as initial water level, stream flows, frictional resistance and duration of the case to generate the simulated flood data. The result of this hydrological model will be converted into TIN (Triangulated Irregular Network) for the visualization purpose. The performed hydrological simulation is adopted by a simpler approach by integrating $1 \mathrm{D}-2 \mathrm{D}$ hydrodynamic model. The 1D-2D approach proved to be suitable for flood simulation. In this context, this model leads to more detailed representations of inundation in coastal urban areas whereas allowing interaction with inland areas (Pasquier et al, 2017). The visualization and analysis can still work if more accurate flood information such as the initial water level, river flow condition, and the high resolution of DEM data is available.

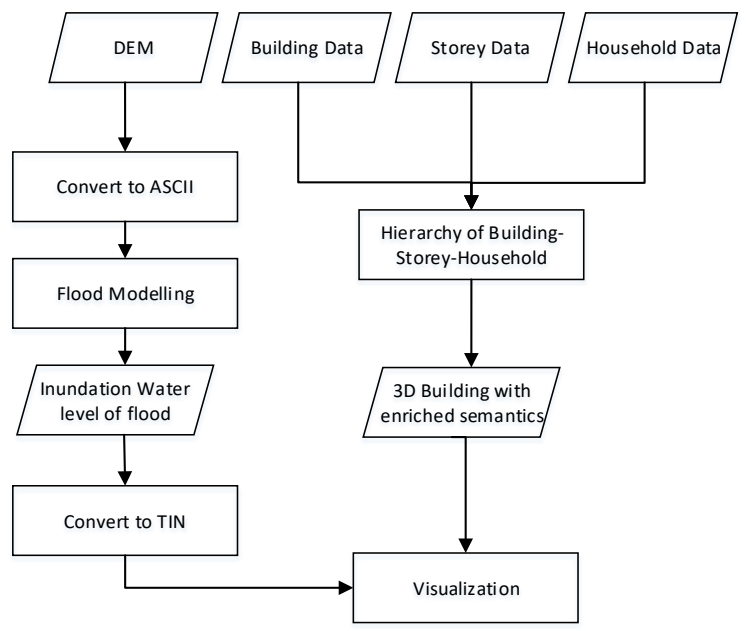

Figure 3. Workflow of 3D flood simulation

There are three analysis that will discuss in this study. First, from the visualization result, it can be determined which building affected by the flood. Second, the inundated water level needs to be calculated to predict the impact of the flood on the building. Lastly, estimate the number of people who trapped inside the building based on the level of the storey affected by the flood in each building.

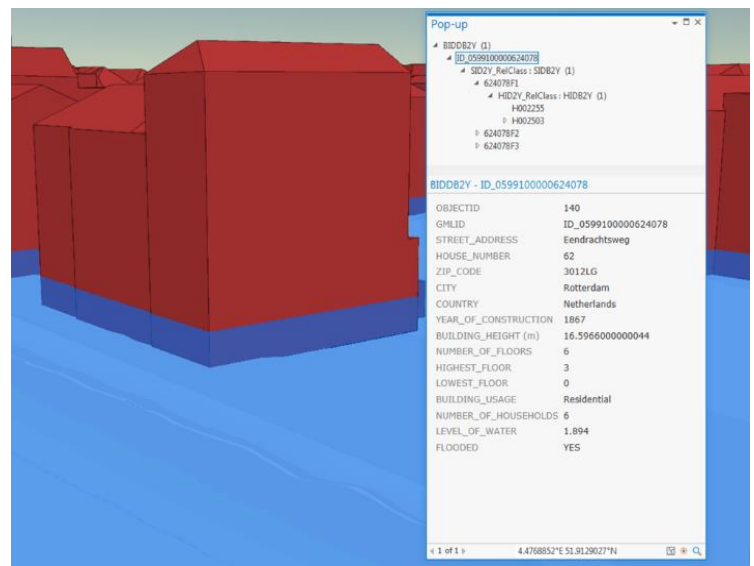

Figure 4. Flooded building information

In this simulation, the results can be assessed visually and also can be analyzed based on the attribute data of the population and households which are affected by the flood. From the visualization result, we can find out the situation and the area affected by the flood. For further information about how the impact of flood to specific building, we can select the building and query the attribute information at different levels. The detailed information about the building is shown in figure 4 . When the affected building is selected, the attribute of the 
building can be seen such as the address, building number, etc. It could be useful to find the location of the building. In addition, it also could be known the height of the water that impact the building. On the storey level, it able to show the information regarding the number of households who lived in the certain floor of building. Furthermore, due to the hierarchy of building-storeyhousehold, the information about the characteristic of people in each household that live at the impacted storey could be illustrated (figure 5).

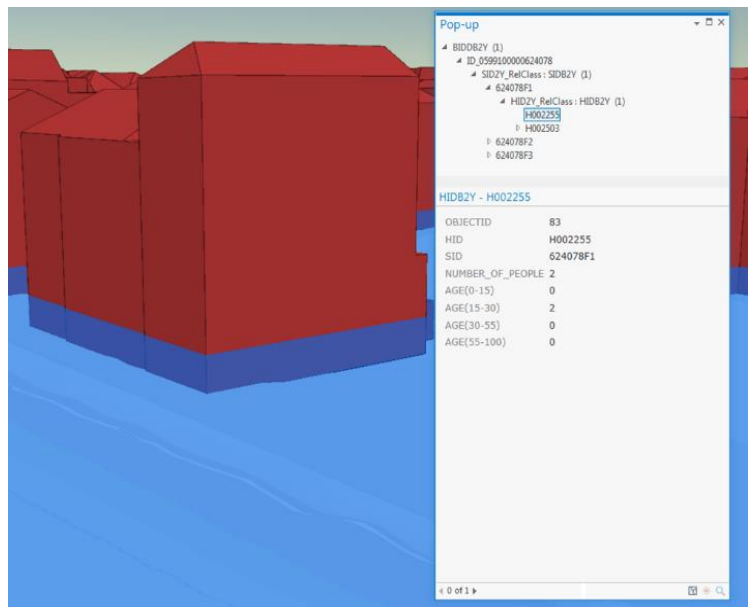

Figure 5. Household information inside flooded building

In figure 7, the simulated water level is visualized along with its appearance in impacting building's façade. Visualization of simulation results should be intuitive to achieve effective communication with users. By giving different colours to buildings affected by flooding (red colour) and those are not affected (green colour), decision-makers can easily identify the building that affected by the flood. This could improve the interpretation of visualization to provide a more intuitive understanding to users.

Figure 8 shows the result of 3D building visualization affected by the flood based on the number of trapped people inside the building. From the simulation result, the average flood height is 1.56 meters. In this simulation it is estimated that each floor has a height of 3.5 meters. As the result, the part of the building affected by flood inundation only reaches the first floor. Decision-makers can easily identify by giving gradient colour to buildings affected by flood based on the number of residents trapped inside. The colour of the building in the visualization above shows how much population in each building trapped by the flood. The red colour indicates that the number of population trapped is more than the yellow building. Therefore, this information can help in the mitigation process.

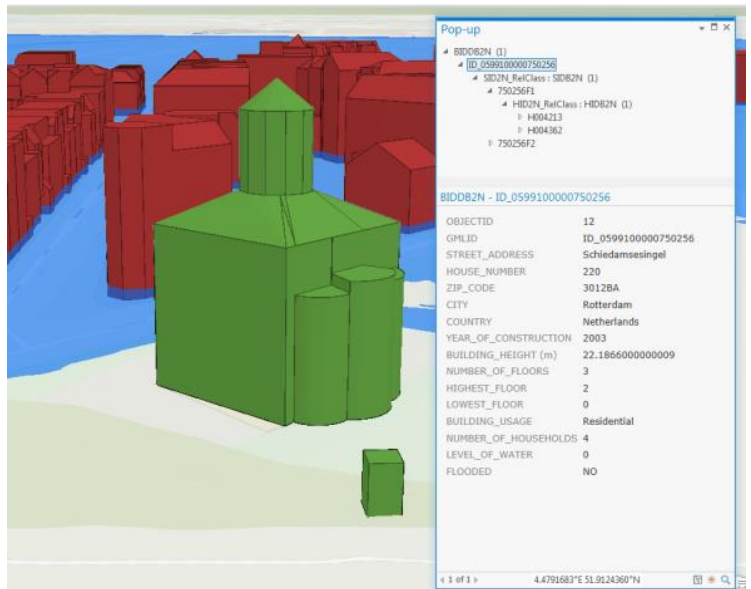

Figure 6. Non-flooded building information

\section{CONCLUSION AND FUTURE WORK}

The main issue of 3D building data for various application especially for disaster management has been identified to ensure data consistency, accuracy, and completeness for decision making. For this reason, within 3D SDI, integrating data between domains of experts and decision-makers became an effective tool. Through SDI, we can collect the data only once and can be used many times according to the application needs. To improve the use of it, we enrich the semantic information of 3D building through created a hierarchy of building-storey-household representation. By applying this hierarchy in a flood simulation, it can make it easier for decision-makers to identify the number of residents who trapped in each building. In addition, this makes it easier in the disaster mitigation process by prioritizing floodaffected buildings that have the highest number of residents. In future, we aim to extend our approach to include more detailed building geometry in the level hierarchy of storey and household. Moreover, we also plan to make the simulation become a realtime interactive tool.

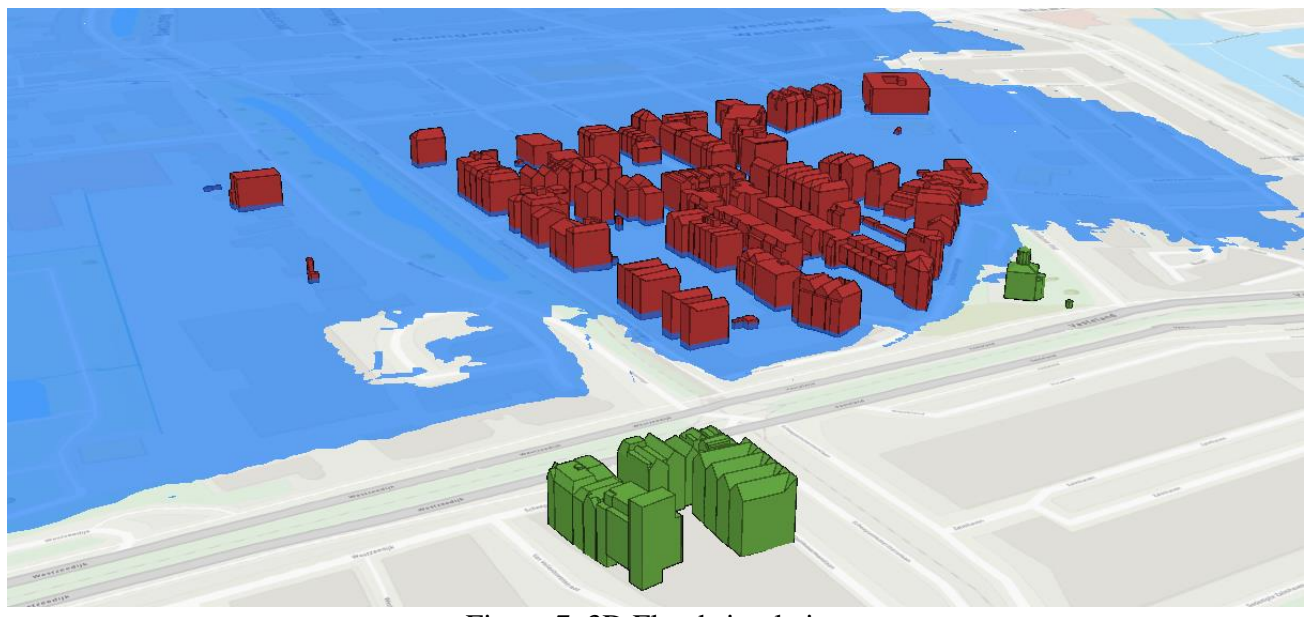

Figure 7. 3D Flood simulation 


\begin{tabular}{|c|c|c|c|}
\hline Authors & Infrastructure Element Dataset & Flood Hazard Spatial Dataset & $\begin{array}{c}\text { Social Indicators } \\
\text { Dataset }\end{array}$ \\
\hline Kumar K., et al (2018) & $\begin{array}{l}\text { Building (LoD1), roads, rail } \\
\text { networks, lakes, canals. }\end{array}$ & TIN, rainfall. & - \\
\hline P. Tymkow, et al (2016) & Building (LoD1 and LoD2). & $\begin{array}{l}\text { DTM, airbone laser scanning, } \\
\text { and land cover. }\end{array}$ & - \\
\hline Filip Biljeki, et al (2015) & $\begin{array}{l}\text { Building (loD1 and LoD2), } \\
\text { address point, bridges, roads, } \\
\text { rail networks, lakes, canals. }\end{array}$ & $\begin{array}{l}\text { DTM, DEM, DSM, and aerial } \\
\text { imagery. }\end{array}$ & - \\
\hline Jantien Stoter, et al (2011) & $\begin{array}{l}\text { Building (LoD1 and LoD2), } \\
\text { bridges, cables and pipelines. }\end{array}$ & DEM, and aerial imagery. & - \\
\hline $\begin{array}{l}\text { Florence Jacquinod and } \\
\text { Julia Bonaccorsi (2019) }\end{array}$ & Building (LoD1). & DEM, and orthophoto. & - \\
\hline $\begin{array}{l}\text { Jeff Larson and Al Shaw } \\
\text { (2013) }\end{array}$ & Building (LoD2). & DEM and flood risk zone map. & - \\
\hline $\begin{array}{l}\text { Costas Armenakis, et al } \\
\text { (2017) }\end{array}$ & $\begin{array}{l}\text { Building footprint, building } \\
\text { address, building type, roads, } \\
\text { and rail networks. }\end{array}$ & $\begin{array}{l}\text { DEM, aerial/satellite imagery, } \\
\text { land use, and land depressions. }\end{array}$ & $\begin{array}{l}\text { Age, marital status, } \\
\text { education level, } \\
\text { income, and } \\
\text { population. }\end{array}$ \\
\hline P. Adda, et al (2010) & $\begin{array}{l}\text { Building (LoD1 and LoD2) and } \\
\text { roads. }\end{array}$ & DEM. & - \\
\hline Lukas Herman, et al (2018) & Building (LoD1). & DTM and aerial imagery. & - \\
\hline $\begin{array}{l}\text { A. K. M. Azad Hossain, et } \\
\text { al (2011) }\end{array}$ & Building (LoD1). & DEM and orthophoto, & - \\
\hline
\end{tabular}

Table 5. Summary of dataset used in previous study

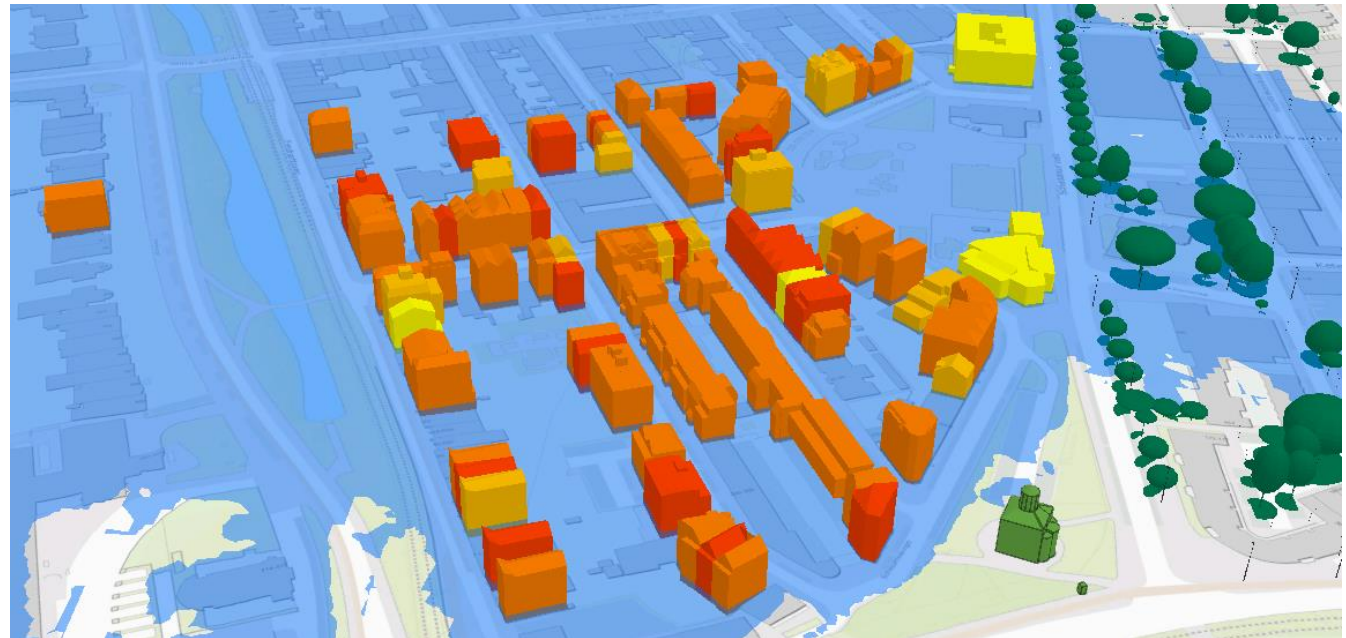

Figure 8. 3D building visualization based on the number of trapped people inside the building

\section{REFERENCES}

Abbas Rajabifard, Ali Mansourian, Mohammad Javad Valadan Zoej, Ian Williamson, 2004. Developing Spatial Data Infrastructure to Facilitate Disaster Management, in Proceedings, GEOMATICS 83 Conference, Tehran, Iran. http://hdl.handle.net/11343/33841

Adda, Patrick., Mioc, Darka., Anton, François., McGillivray, E., Morton, A., Fraser, D. 2010. 3D flood-risk models of government infrastructure. ISPRS Archives. 38. https://www.isprs.org/proceedings/XXXVIII/4-W13/ID_39.pdf.

Alias, A.R., Behnam, A., Volker, C., 2010. Developing a Framework for Malaysian 3D SDI. ISPRS XXXVIII-4/W15. http://www.3dgeoinfo.org/ISPRS_Conference_CD/Paper_ISPR S/Oral/1_3DGeoInfo2010_126_Alias_Coors_Framework_3DS DI.pdf.
A. K. M. Azad Hossain, Yafei Jia, Xinya Ying, Yaoxin Zhang, and Ting Ting Zhu, 2011. Visualization of Urban Area Flood Simulation in Realistic 3D Environment. DOI: $10.1061 / 41173(414) 207$

Belsky, M., Sacks, R., and Brilakis, I., 2016. Semantic enrichment for building information modeling. Comput.-Aided Civ. Infrastruct. Eng., 31(4), 261-274. https://doi.org/10.1111/mice.12128

Biljecki, Filip, 2017. The concept of level of detail in 3D city models. Dissertation TU Delft. ISBN: 978-90-77029-36-7. DOI: 10.4233/uuid:f12931b7-5113-47ef-bfd4-688aae3be248

Bisheng Yang, Qingquan Li, Deren Li., 2000. Building Model Creating and Storing in 3D Urban GIS. International Archives of Photogrammetry and Remote Sensing. Vol. XXXIII, Part B4. Amsterdam

2000 
https://pdfs.semanticscholar.org/2ff9/88239d16f28b71ded5d27f f7826d135a8754.pdf.

Costas Armenakis, et al, 2017. Flood Risk Assessment in Urban Areas Based on Spatial Analytics and Social Factors. Geosciences 2017, 7, 123; doi:10.3390/geosciences7040123

Eastman, C., Teicholz, P., Sacks, R. and Liston, K. 2008. BIM Handbook: A Guide to Building Information Modeling for Owners, Managers, Designers, Engineers, and Contractors. ISBN: 978-0-470-18528-5.

Ehrlich, D., Tenerelli, P., 2013. Optical satellite imagery for quantifying spatio-temporal dimension of physical exposure in disaster risk assessments. Natural Hazards 2013, 68, 1271-1289. doi.org/10.1007/s11069-012-0372-5

European Commission. 2007. Directive 2007/2/EC of the European Parliament and the Council of 14 March 2007 establishing an Infrastructure for Spatial Information in the European Community (INSPIRE). http://eurlex.europa.eu/JOHtml.do?uri=OJ:L:2007:108:SOM: EN:HTML

Filip Biljecki, Jantien Stoter, Hugo Ledoux, Sisi Zlatanova, and Arzu Çöltekin., 2015. Applications of 3D City Models: State of the Art Review. ISPRS Int. J. Geo-Inf. 2015, 4, 2842-2889; doi.org/10.3390/ijgi4042842

Florence Jacquinod and Julia Bonaccorsi, 2019. Studying Social Uses of 3D Geovisualizations: Lessons Learned from ActionResearch Projects in the Field of Flood Mitigation Planning. ISPRS Int. J. Geo-Inf. 2019, 8, 84; doi:10.3390/ijgi8020084

Gerhard Gröger, Lutz Plümer,. 2012. CityGML - Interoperable semantic 3D city models. ISPRS Journal of Photogrammetry and Remote Sensing, Volume 71, 2012, Pages 12-33, ISSN 09242716. https://doi.org/10.1016/j.isprsjprs.2012.04.004.

Jafari Salim, M. 2017. 3D Spatial Information Intended for SDI: A Literature Review, Problem and Evaluation. Journal of Geographic Information System, 9, 535545.https://doi.org/10.4236/jgis.2017.95033

Jeff Larson and Al Shaw, 2013. How We Made the 3-D New York City Flood Map. Propublica https://www.propublica.org/nerds/how-we-made-the-3-d-newyork-city-flood-map. Accessed on 3 July 2019.

J.M. Macay Moreira., F. Nex., G. Agugiaro., F. Remondino., N.J. Lim., 2013. From DSM to 3D Building Models: A Quantitative Evaluation. ISPRS Hannover Workshop 2013, 21 - 24 May 2013 Hannover, Germany. doi.org/10.5194/isprsarchives-XL-1-W1213-2013, 2013

Lukáš Herman, Jan Russnák, and Tomáš Řezník, 2018. Flood Modelling and Visualizations of Floods through 3D Open Data. IFIP Advances in Information and Communication Technology May 2017. DOI: 10.1007/978-3-319-89935-0_12

Kalbani, K. Al, Rahman, A. Abdul, Awadhi, T. Al, Alshannaq, F., 2018. Development of a Framework for Implementing 3d Spatial Data Infrastructure in Oman - Issues and Challenges. ISPRS Volume XLII-4/W9, 2018, pp.243-246. DOI: 10.5194/isprs-archives-XLII-4-W9-243-2018

Kolbe T.H. (2009) Representing and Exchanging 3D City Models with CityGML. In: Lee J., Zlatanova S. (eds) 3D Geo-
Information Sciences. Lecture Notes in Geoinformation and Cartography. Springer, Berlin, Heidelberg. https://doi.org/10.1007/978-3-540-87395-2_2

Kubicek, H., Cimander, R., Scholl, H.J., 2011. Organizational Interoperability in E-Government, Lessons from 77 European Good-Practice Cases. Springer, Heidelberg. ISBN: 978-3-64222501-7

Kumar, Kavisha., Ledoux, H., Stoter, Jantien. 2018. Dynamic 3D Visualization of Floods: Case of The Netherlands. ISPRS International Archives. XLII-4/W10. pp 83-87. DOI: 10.5194/isprs-archives-XLII-4-W10-83-2018

Pasquier, U., He, Yi., Hooton, S. Goulden, Marisa., Hiscock, Kevin M. 2018. An integrated 1D-2D hydraulic modelling approach to assess the sensitivity of a coastal region to compound flooding hazard under climate change. Nat Hazards, pp 1-23. https://doi.org/10.1007/s11069-018-3462-1

P. Tymkow, M. Karpina, A. Borkowski, 2016. 3D GIS for Flood Modelling in River Valleys. ISPRS Congress, 12-19 July 2016, Prague, Czech Republic. DOI: 10.5194/isprsarchives-XLI-B8175-2016

Skakun, S., Kussul, N., Shelestov, A., Kussul, O. 2014. Flood hazard and flood risk assessment using a time series of satellite images: A case study in Namibia. Risk Analysis Journal. 2014, 34, 1521-1537. doi.org/10.1111/risa.12156. DOI: 10.1111/risa. 12156

Stoter J.E., van den Brink L., Vosselman G., Goos J., Zlatanova S., Verbree E. et al., 2011. A generic approach for 3D SDI in the Netherlands. ISPRS workshop on 3D city modelling and applications and the 6th 3D GeoInfo conference, 26-28 June 2011. 2011. p. 327-348.

Sun Xuan., 2015. Semantic 3D Building Model Construction for Smart Urban Management. Conference: 2015 International Conference on Industrial Technology and Management Science. doi.org/10.2991/itms-15.2015.136

T.N. Herzog, F.J. Scheuren, W.E. Winkler, 2007. Data Quality and Record Linkage Techniques, Springer, 2007. DOI: $10.1007 / 0-387-69505-2$

Uznir, U, et al., 2014. 3D Hilbert Space Filling Curves in 3D City Modeling for Faster Spatial Queries. International Journal of 3D Information Modeling. Volume 3 Issue 2, Pages 1-18. DOI 10.4018/ij3dim.2014040101

Yixing Chen, Tianzhen Hong, Xuan Luo, Barry Hooper. 2019. Development of city buildings dataset for urban building energy modelling. Energy and Buildings. Vol 183, Pages 252-265. ISSN 0378-7788. https://doi.org/10.1016/j.enbuild.2018.11.008. 